\title{
The Current Situation of International Accounting Convergence and the Strategic Choice of International Convergence of Accounting Standards for Chinese Enterprises
}

Yu He*

Canvard College, Beijing Technology and Business University, Beijing 101118, China. E-mail: 438025412@qq.com

Abstract: With the deepening of world economic integration, IFRS has become more and more widely used worldwide. Under the new situation that the current international financial regulatory framework is being rebuilt, the international accounting landscape is undergoing major adjustments, and the international accounting standard setting agencies are actively promoting the reform of governance structure, my country needs to review the situation, follow the trend, and choose an international accounting standard that meets the needs of national conditions.

Keywords: Economic Integration; International Financial Reporting Standards; Governance Structure Reform

\section{Introduction}

In the context of accelerating economic globalization, the increasing opening and integration of global capital markets, and the rapid development of information and network technologies, the international convergence of accounting standards has developed by leaps and bounds in recent years, especially in the past decade, and more and more countries or regions have begun join the ranks of converging with IFRS or directly adopting IFRS ${ }^{[1]}$. It is in this context that the convergence of global accounting standards has further accelerated. As the world's largest developing country and an emerging and transitional economy country, how to choose an appropriate international convergence strategy for accounting standards will have a major impact on the development direction of my country's accounting standards, corporate reforms, and the opening up of capital markets.

\section{The effectiveness of international convergence of my country's corporate accounting standards and the current situation of international accounting convergence}

\subsection{The effectiveness of international convergence of my country's corporate accounting standards}

Since the reform and opening up, my country has been following the trend and actively promoting the internationalization and international convergence of my country's corporate accounting standards, laying a solid foundation for the sustainable development of my country's economy and its integration into the world economic system. Under the guidance of the Five Principles of International Accounting Convergence on "Convergence is the direction, convergence is not equal to equality, convergence is the process, convergence is interaction, and convergence is the new starting

This is an open-access article distributed under the terms of the Creative Commons Attribution Non-Commercial License

(http://creativecommons.org/licenses/by-nc/4.0/), which permits unrestricted non-commercial use, distribution, and reproduction in any medium, provided the original work is properly cited. 
point", Vice Minister Wang Jun of the Ministry of Finance, with the joint efforts of the majority of accounting colleagues, my country has established a system of corporate accounting standards that is convergent with the International Financial Reporting Standards and has achieved historic breakthroughs. In recent years, the international convergence of Chinese corporate accounting standards has achieved remarkable results, attracting worldwide attention ${ }^{[2]}$.

\subsection{The current situation of international accounting convergence}

(1) The international financial regulatory framework is being restructured, and the international coordination of financial regulation is increasingly strengthened, which puts forward higher requirements on the International Financial Reporting Standards. In the post-international financial crisis era, international organizations and governments have taken measures to reform the financial system to maintain the stability of the international financial system and promote the recovery of the world economy. On the one hand, the G20 and the Financial Stability Board require strengthening the supervision of systemic risks, strengthening international cooperation, and establishing early warning and handling mechanisms to deal with systemic financial risks. On the other hand, various regulatory agencies strive to formulate a complete set of new standards and effective implementation models for financial supervision to conduct prudential supervision of financial institutions ${ }^{[3]}$.

(2) International accounting standard setting institutions are actively promoting the reform of governance structure and enhancing the global recognition of IFRS. In order to improve the transparency of financial reporting and the quality of accounting information, the International Accounting Standards Board and the International Financial Reporting Standards Foundation hope to review the appropriateness of the objectives of the IFRS Foundation, the current governance of the foundation, and the fiduciary responsibilities of the supervisory committee and its membership and other governance structure issues not only promote the realization of the goal of the International Accounting Standards Board to formulate high-quality global accounting standards, but also maintain the public fiduciary responsibility and independence of the International Accounting Standards Board. This will increase the global recognition of International Financial Reporting Standards, the International Accounting Standards Board, and the International Financial Reporting Standards Foundation.

(3) The International Accounting Standards Board hopes that countries and regions in the world can fully adopt IFRS, instead of just staying at the level of convergence, in order to truly achieve the goal of using the same set of accounting standards globally. The International Accounting Standards Board believes that convergence is only a means, and the ultimate goal is to fully adopt it. Only when countries and regions fully adopt IFRS can they fully obtain the benefits of using IFRS.

\section{The main strategies of countries or regions in the world currently ap- plying IFRS}

\section{1 "Direct Adoption" model}

Under the "Direct Adoption" model, the accounting standards of a country or region will completely adopt the International Financial Reporting Standards without change, and the country or region will no longer retain the right to set accounting standards. In other words, the country or region does not need to perform any approval or revision procedures in the process of adopting IFRS. At present, only a few countries or regions in the world adopt the mode of directly adopting the International Financial Reporting Standards issued by the International Accounting Standards Board $^{[4]}$.

\section{2 "Convergence" model}

Under the "Convergence" model, the standard setting agencies of these countries or regions do not directly incorporate the International Financial Reporting Standards issued by the International Accounting Standards Board into their accounting standard system, but retain the standard setting power of local accounting standards. Countries or re- 
gions that adopt the "Convergence" strategy will not copy the International Financial Reporting Standards exactly without changing it. Instead, they will be consistent with the International Financial Reporting Standards in terms of accounting treatment principles and methods, and retain some content with their own national characteristics.

\section{3 "Recognition" model}

Under the "Recognition" model, a country or region decides to adopt a certain IFRS before the statutory body implements the recognition procedure. In the process of recognizing IFRS, statutory bodies in these countries or regions may revise the proposed IFRS.

\section{4 "Convergent Recognition" model}

Under the "Convergence Recognition" model, a country or region will promote the convergence of its own accounting standards and international financial reporting standards, while retaining its own accounting standard setting agencies and their power to formulate their own accounting standards, and recognize the current international financial reporting standards one by one, and further issue guidelines, explanations or other disclosure requirements based on the actual situation in the country ${ }^{[5]}$.

\section{Choose the international convergence strategy of my country's account- ing standards based on the international and domestic situations}

\subsection{The adoption of the "Convergence" model conforms to my country's legal environment}

The Chinese Accounting Law clearly stipulates that "The country implements a unified accounting system. The national unified accounting system shall be formulated and promulgated by the financial department of the State Council in accordance with this law." Chinese enterprises must follow the national unified accounting system established by the Ministry of Finance, such as corporate accounting guidelines. Judging from the provisions of my country's accounting law, the "Direct Adoption" strategy lacks legal basis and does not meet the requirements of my country's accounting law. At the same time, it may also cause my country to lose its independent right to set accounting standards. Under the "Convergence" model, the accounting standards for business enterprises are still the unified national accounting system formulated by my country's financial departments in accordance with the accounting law. This fundamental principle has not changed, but it is in line with the International Financial Reporting Standards in terms of accounting treatment principles and confirmation measurement methods. Be consistent.

\subsection{Adopting the "Convergence" model is helpful to the implementation of corporate ac- counting standards}

The IFRS system starts from the conceptual framework, and then expands layer by layer. The accounting standards are also quite principled. There is a certain gap between the education and existing knowledge received by the majority of accountants in my country. If the International Financial Reporting Standards are directly adopted, it may cause certain difficulties for the relevant accounting personnel of our country to carry out relevant accounting treatments. For example, the report format of the International Financial Report is too general, and there is no specific accounting subject corresponding to the financial report. Each enterprise can design its own report format and determine the name of the accounting subject according to the actual business, which makes even the same industry. There are also some differences in the financial statements of the companies within. However, our country has stipulated a unified report format in the corporate accounting standards, and set up a relatively complete accounting subject according to the report items, which will help our accountants to carry out daily accounting processing and financial report preparation.

\subsection{Adopting the "Convergence" model is conducive to maintaining a certain degree of flexi- bility in the process of constant changes in IFRS}

At present, the financial instruments, insurance contracts, income, leases and other items in the International Fi- 
nancial Reporting Standards have not yet issued final standards. The coordination with the US generally accepted accounting principles is in progress, and the European Union has not made a clear statement on the latest financial instruments and other standards. For this reason, the final decision of the International Accounting Standards Board and its impact are uncertain. In this case, China adopts a strategy of "Convergence" to ensure that China will assess the situation, make rational decisions, and grasp the situation flexibly when facing the continuous changes in IFRS, so as to prevent the changes in IFRS from affecting China's economy and corporate development unnecessary shock.

\subsection{Adopting the "Convergence" model to facilitate timely and effective resolution of China's accounting practice problems}

It is an important task of my country's accounting reform to formulate accounting standards for enterprises and promote the convergence with the International Financial Reporting Standards. However, the fundamental starting point for accounting standards is still to standardize the accounting practices of my country's enterprises and solve the problems of my country's accounting practices. Based on this, the construction of accounting standards for enterprises in my country adopts the "Convergence" model instead of the "Direct Adoption" model, which is a pragmatic and effective measure. For example, there are a large number of business combinations within the same group in my country, which are business combinations under the same control, and the International Financial Reporting Standards have not yet clearly regulated this aspect. Assuming that we adopt the "Direct Adoption" model, there will be gaps in accounting standards, resulting in unruly accounting practices. Even if we wait for the International Accounting Standards Board to issue new standards or revise existing standards for these items, it will be a series of necessary procedures such as project establishment, research, solicitation of opinions, voting, and standard issuance require a long wait, which is not conducive to the improvement of the quality of accounting information and the improvement of accounting work order in my country's enterprises.

\section{Conclusion}

The "Convergence" strategy is my country's better choice to deal with the current situation on the road to the internationalization of accounting standards, and it is also a rational decision that suits my country's current national conditions. We should be based on domestic actual conditions under the policy guidance of continuous convergence with IFRS, conform to the general trend of international accounting convergence, deeply participate in the formulation and revision of important IFRS projects, improve China's corporate accounting standards system, and strive to compete with more countries or regional equivalent accounting standards will lay a solid foundation for the reform of the international financial system, the opening and stability of China's economy, the prosperity and development of the capital market, and the implementation of the "going global" strategy of domestic enterprises, enhancing international influence and voice, and safeguarding the interests of our country and enterprises.

\section{References}

1. Chai J, Liu J. Comparison and convergence between my country's accounting standards and international accounting standards (in Chinese). Oriental Enterprise Culture 2015; (19): 264.

2. Cheng Y. Thoughts on the convergence of my country's accounting standards to international accounting standards (in Chinese). Journal of Hubei University of Economics (Humanities and Social Sciences) 2016; 13(2): 76 - 77.

3. Ji Y. Discussion on the international convergence of my country's accounting standards. Finance and Economics, 2016, (3): 253.

4. Liu C. Talking about the convergence and difference between my country's Accounting Standards for Business Enterprises (CAS) and International Financial Reporting (IFRS) (in Chinese). Contemporary Accounting 2015; (1): $11-12$.

5. Peng Y. Research on the difference and convergence between my country's current accounting standards and international accounting standards (in Chinese). Money China 2016; (3): 155. 